\title{
Downregulated connexin32 promotes EMT through the Wnt/ $\beta$-catenin pathway by targeting Snail expression in hepatocellular carcinoma
}

\author{
YAN YANG $^{1 *}$, NA ZHANG ${ }^{2 *}$, JIAN ZHU $^{3}$, XIAO-TING HONG ${ }^{4}, \mathrm{HAO} \mathrm{LIU}^{5}$, \\ YU-RONG OU ${ }^{2}$, FANG SU ${ }^{1}$, RUI WANG ${ }^{1}$, YU-MEI LI ${ }^{1}$ and QIONG WU ${ }^{1}$ \\ Departments of ${ }^{1}$ Medical Oncology, ${ }^{2}$ Pathology, and ${ }^{3}$ Cardiovasology, \\ The First Affiliated Hospital of Bengbu Medical College, Bengbu, Anhui 233004; ${ }^{4}$ Cancer Research Center, \\ Department of Basic Medical Sciences, Medical College, Xiamen University, Xiamen, Fujian 361102; \\ ${ }^{5}$ Department of Pharmacy, Bengbu Medical College, Bengbu, Anhui 233000, P.R. China
}

Received February 22, 2017; Accepted April 19, 2017

DOI: $10.3892 /$ ijo.2017.3985

\begin{abstract}
Hepatocellular carcinoma (HCC) is one of the common malignances in the world and is associated with high mortality and poor prognosis, partly due to early invasion and metastasis. Cx32 has been indicated to be involved in the progression of many cancers including HCC, but its relationship with tumor invasion and metastasis is still controversial. In the present study, the downregulated $\mathrm{Cx} 32$ in HCC tissue was found negatively correlated with histological grade and lymph node metastasis. Cx32 regulated HCC migration and invasion in vitro and inhibited tumor metastasis in xenograft models in vivo. We subsequently identified that $\mathrm{Cx} 32$ mediated epithelial-mesenchymal transition (EMT) by regulating Snail expression, and the enhanced Snail was due to activation of Wnt/ $\beta$-catenin signaling in response to $\mathrm{Cx} 32$ inhibition. Finally, decreased expression of $\mathrm{Cx} 32$ showed strong correlation with loss/reduction of E-cadherin, higher expression of Snail, and nuclear accumulation of $\beta$-catenin in HCC tissues. Taken together, our results suggest that $\mathrm{Cx} 32$ inhibits HCC invasion and metastasis through Snail-mediated EMT, Cx32 and this signaling pathway molecules may offer potential targets for HCC cancer therapy.
\end{abstract}

Correspondence to: Dr Qiong Wu, Department of Medical Oncology, The First Affiliated Hospital of Bengbu Medical College, Bengbu, Anhui 233004, P.R. China

E-mail: qiongwu68@outlook.com

${ }^{*}$ Contributed equally

Abbreviations: Cx32, connexin32; EMT, epithelial-mesenchymal transition; GJ, gap junction; HCC, hepatocellular carcinoma; H\&E, hematoxylin and eosin; IHC, immunohistochemistry; NC, negative control

Key words: hepatocellular carcinoma, connexin32, epithelialmesenchymal transition, tumor invasion, Snail

\section{Introduction}

Hepatocellular carcinoma (HCC) is the fifth most common malignancy in the world and the second leading cause of mortality among malignant tumors (1). At present, surgery is the main strategy for long-term survival of patients with HCC. However, even with radical resection, $60-70 \%$ of patients will present with recurrence and metastasis within 5 years (2). In addition, $\sim 80 \%$ of patients with $\mathrm{HCC}$ have distant metastases at the time of diagnosis and surgical resection may not be possible. Palliative care carries a 5-year survival rate of only 5-7\% (3). The highly invasive nature of HCC, metastasis and recurrence are the main causes of poor prognosis and high mortality. Therefore, effective prevention and treatment for the invasion and metastasis of HCC are important measures to improve its prognosis. However, at present, the precise underlying molecular mechanisms of HCC invasion and metastasis remain to be elucidated.

Epithelial-mesenchymal transition (EMT) refers to the process of transformation of epithelial cells to mesenchymal phenotypic cells resulting in increased motility and invasiveness. During this process, cells lose polarity, cell-cell adhesion, epithelial markers such as E-cadherin, and acquire mesenchymal properties with high expression of mesenchymal molecular markers including vimentin, Snail, Slug and Twist (4). A number of studies have shown that EMT plays a crucial role in liver cancer invasion and metastasis (5-7), nevertheless, there is a lack of clear picture in HCC of the overall EMT signaling network. Recently, the potential link between Connexin (Cx) (8) or gap junction (GJ) (9) and EMT has been rendered.

$\mathrm{Cx}$, the structural protein of GJs, exerts its biological and cellular functions through both GJ-dependent and GJ-independent pathways (10). In liver tissues and cell lines, Cx 32 and Cx26 are predominantly expressed and contribute to the major component of hepatocyte GJs (11). Decreased GJ function caused by not only the reduced Cx expression level but also their aberrant cytoplasmic localization has been indicated in carcinogenic processes $(10,12)$. Cx32 is often 
Table I. siRNAs targeting specific genes.

Sequence

\begin{tabular}{llc}
\cline { 2 - 3 } Gene & \multicolumn{1}{c}{ Sense (5'-3') } & Antisense (5'-3') \\
\hline Cx32 siRNA1 & GCUCCCUGAAAGACAUACUTT & AGUAUGUCUUUCAGGGAGCTT \\
Cx32 siRNA2 & GCCGUCUUCAUGUAUGUCUTT & AGACAUACAUGAAGACGGCTT \\
Cx32 siRNA3 & GCAACACAUAGAGAAGAAATT & UUUCUUCUCUAUGUGUUGCTT \\
Snail siRNA1 & GCUGCAGGACUCUAAUCCATT & UGGAUUAGAGUCCUGCAGCTT \\
Snail siRNA2 & GCCUUCAACUGCAAAUACUTT & AGUAUUUGCAGUUGAAGGCTT \\
Snail siRNA3 & CAGAUGUCAAGAAGUACCATT & UGGUACUUCUUGACAUCUGTT \\
Control & UUCUCCGAACGUGUCACGUTT & ACGUGACACGUUCGGAGAATT
\end{tabular}

recognized as a tumor suppressor gene $(13,14)$, however, the paradigm that Cxs are of universal benefit by restricting tumor progression has been challenged (10). Several reports suggest that Cxs might facilitate tumor migration, invasion and metastasis (15-17). Thus, the relationship between Cxs and tumor invasion, and also the role of EMT in the process are needed to be clarified.

In the present study, we first defined the expression of $\mathrm{Cx} 32$ in HCC tissue samples and its possible relationship with clinicopathological parameters. The effect of Cx32 on HCC invasion and metastasis was observed both in vitro and in vivo. We also investigated whether $\mathrm{Cx} 32$ plays its role by regulating EMT as well as being a basis for a possible molecular mechanism.

\section{Materials and methods}

HCC samples and cell lines. Archival normal liver (20 cases) and HCC (76 cases) paraffin blocks were collected as described in an earlier study (18) to determine the relationship of $\mathrm{Cx} 32$ expression to clinicopathological parameters. Another set of 34 cases of archival paraffin-embedded formalin-fixed HCC tissues were also collected at our institution from January 2014 to June 2015 to define the correlation between Cx32 and other indicators. The use of the tissue samples was approved by the Medical Ethics Committee of Bengbu Medical College (Bengbu, China). Human normal hepatic cell line LO2, hepatocellular carcinoma cell lines HepG2, Huh7 and SMMC-7721 were cultured at $37^{\circ} \mathrm{C}$ in $5 \% \mathrm{CO}_{2}$ in Dulbecco's modified Eagle's medium (DMEM; Invitrogen, Carlsbad, CA, USA) supplemented with $10 \%$ fetal bovine serum (FBS; HyClone Laboratories, Inc., Logan, UT, USA).

Hematoxylin and eosin $(H \& E)$ staining and immunohistochemistry $(I H C)$. H\&E and IHC staining was performed as previously described (18). The Cx32 immunoreactivity was performed using a combined scoring system based on the fraction of positive tumor cells and the predominant staining intensity in the tumors as described by Regidor et al (19). The cell membranous staining of E-cadherin was also evaluated semi-quantitatively and the tumors were divided into two groups: i) preserved pattern: $\geq 75 \%$ of tumor cells showed equivalent membranous staining to adjacent normal bile duct epithelium; and ii) reduced pattern: $<75 \%$ of tumor cells showed membranous staining (20). For Snail and $\beta$-catenin, nuclear staining was considered as positive if at least one tumor cell had a stained nucleus. The primary antibodies and dilutions used were as follows: Cx32 (1:100; Sigma-Aldrich, St. Louis, MO, USA); E-cadherin (1:50; Abcam, Cambridge, MA, USA); Snail (1:150; Abcam); and $\beta$-catenin (1:200; Santa Cruz Biotechnology, Santa Cruz, CA, USA).

Expression plasmids and gene silencing. The $\mathrm{pEX}-2$ plasmids containing the full-length cDNA of human Cx32 (Gene ID: 2705) and Snail (Gene ID: 6615), were purchased from Suzhou GenePharma Co., Ltd. (Suzhou, China). Empty plasmid pEX-2 was used as a negative control. Cx32 and Snail siRNA fragments were also synthesized and supplied by GenePharma. The specific siRNA sequences are listed in Table I. Transfection reagent was Lipofectamine ${ }^{\mathrm{TM}} 2000$ (Invitrogen) and experiments were conducted strictly according to the instructions.

Establishment of stable cell line overexpressing hCx32. Lentivirus particles expressing hCx32 and negative control (NC) were purchased from GenePharma. Huh7 cells were seeded in a 24 -well plate until the cells grew to $40 \%$ confluency and were then transduced with the lentivirus in the presence of polybrene ( $5 \mu \mathrm{g} / \mathrm{ml}$; Sigma-Aldrich) using Lipofectamine 2000. After 2 days of transfection, the cells were cultured in a selective medium containing puromycin $(0.75 \mu \mathrm{g} / \mathrm{ml}$; Sigma-Aldrich). After 2-3 weeks of cultivation, the puromycinresistant monoclonal cells were selected and cultured under the selective pressure of $0.75 \mu \mathrm{g} / \mathrm{ml}$ puromycin to establish the stable overexpressed LV5-hCx32 cell line (Huh7-hCx32) or LV5 lentiviral vector cell line (Huh7-vec).

Cell proliferation study by MTT assay. The Huh7 parental and transfected cells were seeded at 3,000 cells/well into a 96-well plate and cultured for the indicated time. MTT assay was performed as previously described (18).

Clone formation assay. The Huh7 parental and transfected cells were cultured in 6-well plates at 500 cells/well and grown for $10-14$ days at $37^{\circ} \mathrm{C}$ in $5 \% \mathrm{CO}_{2}$. After fixation with methanol, colonies were stained with $0.1 \%$ crystal violet for $10 \mathrm{~min}$ and were washed. The colonies was counted and imaged under a light microscope. 
Table II. The primers used for qRT-PCR analysis.

\begin{tabular}{lllc}
\hline & \multicolumn{2}{c}{ Sequence } & \\
\cline { 2 - 3 } Gene & \multicolumn{1}{c}{ Sense (5'-3') } & \multicolumn{1}{c}{ Antisense (5'-3') } & Product size (bp) \\
\hline Cx32 & GCGTGAACCGGCATTCTA & CCCTCAAGCCGTAGCATTT & 295 \\
Snail & CGGAAGCCTAACTACAGCGA & GGACAGAGTCCCAGATGAGC & 151 \\
$\beta$-actin & TCCTCCTGAGCGCAAGTACTC & GCATTTGCGGTGGACGAT & 130 \\
\hline
\end{tabular}

Transwell invasion and wound healing assay. Transwell invasion assay and wound healing assay were performed as previously described (21). Invasion assay was performed using a Transwell system ( $8 \mu \mathrm{m}$ pore size; Millipore, Billerica, MA, USA). Cells were plated onto the upper chamber with Matrigel (BD Biosciences, San Jose, CA, USA) for $24 \mathrm{~h}$. For the wound healing assay, photographic images were taken from $\mathrm{HCC}$ and HCC transfected cells at 0 and $24 \mathrm{~h}$ under an inverted microscope.

Western blot analysis, RNA isolation and qRT-PCR assay. Western blot analysis, RNA isolation and qRT-PCR assay were described in our previous study (21). The primary antibodies and dilutions used for western blot assay were as follows: Cx32 (1:500; Sigma-Aldrich); E-cadherin (1:1,000; Abcam); vimentin (1:1,000; Abcam); Snail (1:1,000; Abcam); Slug (1:2,000; Abcam); Twist-1 (1:2,000; Abcam); $\beta$-catenin (1:500; Santa Cruz Biotechnology); p- $\beta$-catenin (Y654) (1:100; Abcam); Wnt-1 (1:200; Santa Cruz Biotechnology); and $\beta$-actin (1:500; Santa Cruz Biotechnology). The primers for qRT-PCR assay are listed in Table II. Gene and protein expression levels were normalized to those of internal controls ( $\beta$-actin).

Immunofluorescence. The experimental procedure was performed according to our previous report (18). The concentrations of primary antibodies were used all at 1:200 (diluted with $2 \%$ BSA). Alexa 488- or 568-conjugated secondary antibody was added for $1 \mathrm{~h}$ in the dark at room temperature. The cells were examined and photographed under a fluorescence microscope (Olympus).

In vivo metastasis analysis. Male $\mathrm{BALB} / \mathrm{c} \mathrm{nu} / \mathrm{nu}$ nude mice (5-6-week old) of SPF level were purchased from the Animal Center of the Chinese Academy of Medical Sciences (Shanghai, China). Mice were first randomized into two groups, and the Huh7-hCx32 cells and Huh7-vec cells $\left(1 \times 10^{8}\right)$ were then respectively inoculated subcutaneously into the right side of the backs of mice to imitate tumor metastasis ( $n=8$ for each group). The mice were sacrificed after 8 weeks of implantation, and the tumors, livers and bilateral lungs were removed and embedded in paraffin for pathological examination. All animal experiments were approved by the Animal Care and Use Committee of Bengbu Medical College (Bengbu, China).

Statistical analysis. Results were analyzed with SPSS version 19.0 software (SPSS, Inc., Chicago, IL, USA). Differences between the groups are illustrated in Table III and evaluated by $\chi^{2}$ test. Correlation analysis was performed using the Spearman
Table III. Relationship between Cx32 expression and clinicopathological parameters of 76 HCC samples.

\begin{tabular}{|c|c|c|c|c|}
\hline & & Cx32 & & \\
\hline Variables & $\mathrm{n}$ & $-\quad+$ & value & P-value \\
\hline
\end{tabular}

$\begin{array}{lrrrrr}\begin{array}{l}\text { Age (years) } \\ <60\end{array} & 60 & 33 & 27 & 0.289 & 0.778 \\ \geq 60 & 16 & 10 & 6 & & \\ \text { Sex } & & & & & \\ \quad \text { Male } & 61 & 34 & 27 & 0.089 & 1.000 \\ \quad \text { Female } & 15 & 9 & 6 & & \\ \text { Tumor size }(\mathrm{cm}) & & & & & \\ \leq 5 & 43 & 22 & 21 & 1.182 & 0.352 \\ >5 & 33 & 21 & 12 & & \end{array}$

Edmondson type

$\begin{array}{lrrrrr}\text { I-II } & 48 & 22 & 26 & 6.124 & 0.017^{\mathrm{a}} \\ \text { III-IV } & 28 & 21 & 7 & & \end{array}$

TNM stage

$\begin{array}{lrrrrr}\text { I-II } & 54 & 30 & 24 & 0.080 & 0.805 \\ \text { III-IV } & 22 & 13 & 9 & & \end{array}$

Hepatopathy background

$\begin{array}{llllll}\text { Present } & 60 & 35 & 25 & 0.357 & 0.581\end{array}$

Absent

$\begin{array}{lll}16 & 8 & 8\end{array}$

Lymph node metastasis

$\begin{array}{lrrrrr}\text { Negative } & 62 & 31 & 31 & 5.930 & 0.018^{\mathrm{a}} \\ \text { Positive } & 14 & 12 & 2 & & \end{array}$

Intrahepatic vascular embolism

$\begin{array}{lrrrrr}\text { Present } & 20 & 12 & 8 & 0.129 & 0.796 \\ \text { Absent } & 56 & 31 & 25 & & \end{array}$

${ }^{\mathrm{a}} \mathrm{P}<0.05 ; \chi^{2}$ test.

analysis. Numerical data were presented as means \pm SEM and compared with unpaired Student's t-test. Differences with $\mathrm{P}<0.05$ were considered significant.

\section{Results}

Expression of Cx32 in HCC and its clinical significance. Our previous study found that compared with normal liver tissue, 
A
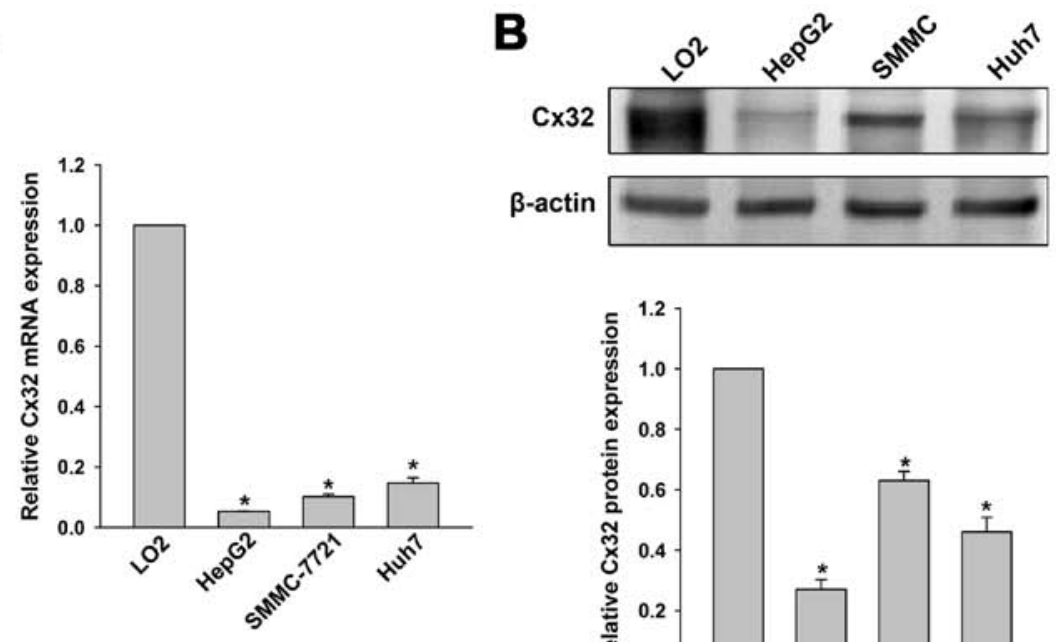

$\beta$-actin
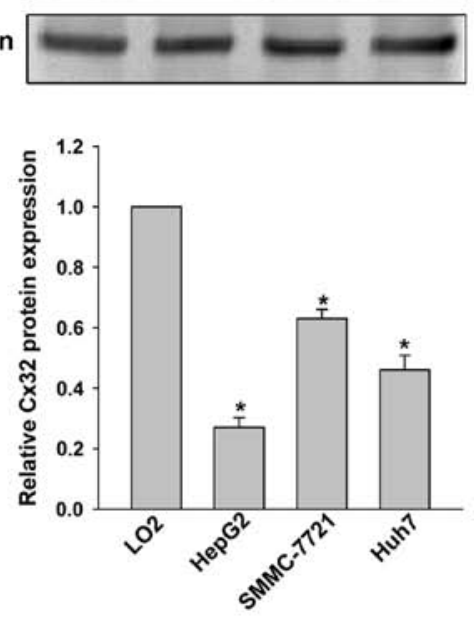

C
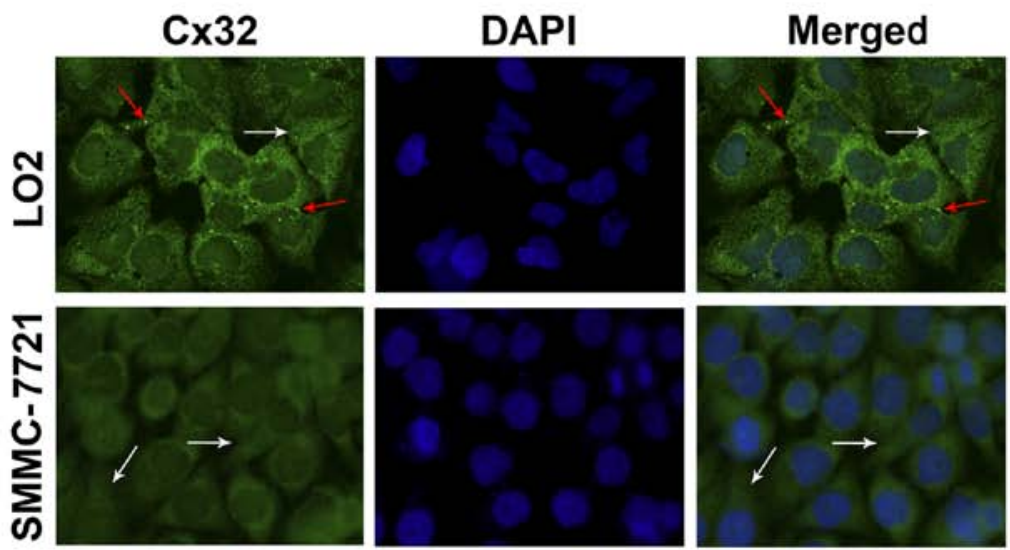

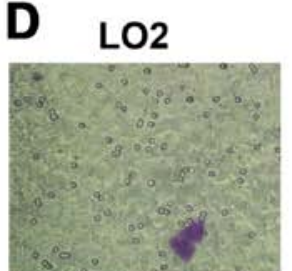

SMMC-7721

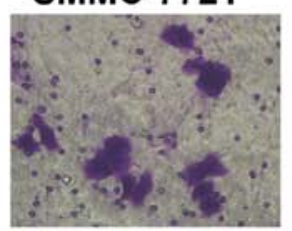

HepG2

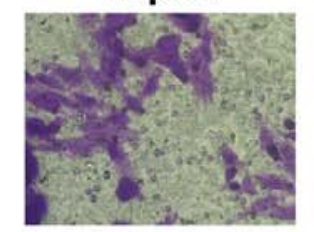

Huh7

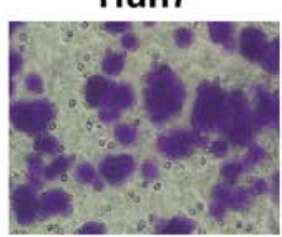

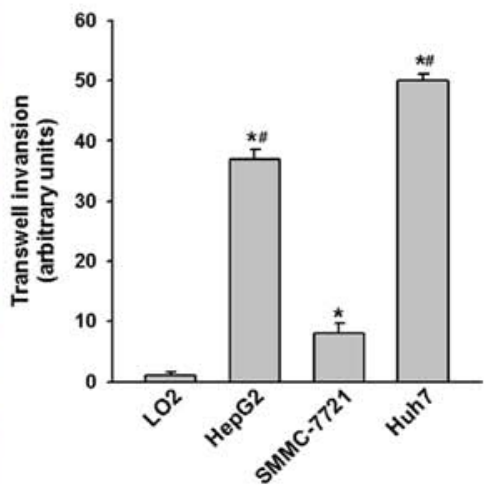

Figure 1. Cx32 is aberrantly expressed and localized in cell lines and correlates with cell invasiveness. (A) qRT-PCR assay was performed to detect the mRNA level of Cx32 in human normal hepatic cell line LO2 and HCC cell lines HepG2, SMMC-7721 and Huh7, respectively. (B) Western blot analysis was conducted to detect the protein level of $\mathrm{Cx} 32$ in the above cell lines. (C) Immunofluorescence assay was used to detect the expression and localization of Cx32 in LO2 and SMMC-7721 cells (original magnification, $\mathrm{x} 400$ ). Both membranous (marked by red arrow) and cytoplasmic (marked by white arrow) localization of Cx32 was observed in LO2 cells, while SMMC-7721 cells displayed a decreased Cx32-specific positive spots, predominantly located in the cytoplasm. (D) Transwell invasion assays of LO2, HepG2, SMMC-7721 and Huh7 cells (original magnification, x400). Data represent the mean \pm SEM of three to five independent experiments. ${ }^{*} \mathrm{P}<0.01$ vs. LO2; ${ }^{\text {P }}<0.01$ vs. SMMC-7721.

the expression of $\mathrm{Cx} 32$ in $\mathrm{HCC}$ tissue is downregulated, and the positively expressed protein shows significant ectopic expression from the cell membrane to the cytoplasm (18). We further analyzed its relationship to clinicopathological characteristics and found that the expression of Cx32 was not correlated with age, sex, tumor size, TNM stage, background of liver disease, 
or vascular embolus (all $\mathrm{P}>0.05$ ), but negatively correlated with histological grade and lymph node metastasis (all $\mathrm{P}<0.05)$ (Table III).

To verify the histological results, Cx32 expression in three HCC cell lines (HepG2, SMMC-7721 and Huh7) and the normal hepatic cell line (LO2) were examined. Results showed that Cx32 at mRNA and protein levels in HCC cells were significantly decreased compared with the LO2 cells (Fig. 1A and B). Immunofluorescence assay further demonstrated that $\mathrm{Cx} 32$ was expressed in membrane and cytoplasm of LO2 cells, while Cx32 mainly located in the cytoplasm in SMMC-7721 cells (Fig. 1C). Thus, we confirmed that Cx32 was downregulated as well as ectopically expressed during hepatocarcinogenesis.

Cx32 negatively regulates $H C C$ migration and invasion in vitro and metastases in vivo. Histological results suggested a potential link between $\mathrm{Cx} 32$ and $\mathrm{HCC}$ invasive and metastatic capacities, therefore, relevant in vitro and in vivo experiments were conducted. As shown in Fig. 1D, LO2 cells had the highest expression of $\mathrm{Cx} 32$ but did not show significant invasion ability. SMMC-7721 cells had a higher expression of Cx32 than HepG2 and the HuH-7 cells, but the invasive potential was significantly lower than that of the latter two HCC cell lines. To investigate whether $\mathrm{Cx} 32$ inhibits malignant phenotype of HCC cells, we first established SMMC-7721 cells by silencing the Cx32 expression by siRNA. On the contrary, HepG2 cells were transfected with Cx32 cDNA to upregulate Cx32 expression. Western blot analysis showed that the expression of $\mathrm{Cx} 32$ was significant downregulated in SMMC-7721 cells with siRNA1 exhibiting the most inhibition, while the expression of $\mathrm{Cx} 32$ was significantly upregulated in HepG2 cells following transfection with Cx32 cDNA (Fig. 2A). Immunofluorescence also confirmed the successful establishment of Cx32 expression-regulated HCC cell models (Fig. 2B). The invasion ability of SMMC-7721 cells was significantly enhanced by $\mathrm{Cx} 32$ downregulation, and the invasive ability of HepG2 cells was significantly decreased by Cx32 upregulation (Fig. 2C). Similar results were also shown in wound healing assay (Fig. 2D).

To further explore whether $\mathrm{Cx} 32$ could inhibit the HCC metastatic potential in vivo, Huh7-hCx32 and Huh7-vec cells were transplanted into BALB/c nude mice by subcutaneous implantation as described in Materials and methods. Consistent with previous reports that $\mathrm{Cx} 32$ inhibited hepatocellular proliferation $(22,23)$, our in vitro experiments showed that cell growth and proliferation of Huh7-hCx32 were significantly slower than those of Huh7-vec cells (data not shown). In vivo experiments showed the mice in both groups developed tumors, however, the Huh7-hCx32 tumors were significantly smaller than the Huh7-vec tumors. More importantly, 6 out of 8 mice in the Huh7-vec group developed lung metastasis, while no metastasis was observed in the Huh-hCx32 group (Fig. 2E).

Cx32 affects EMT and MET process in HCC cells. Since the migration and invasion of tumor cells are closely related to EMT, we then tested whether $\mathrm{Cx} 32$ could affect EMT of HCC cells. Compared with the NC group, Cx32 downregulation in SMMC-7721 cells led to apparent changes in the morphology compatible with EMT, which included elongated, spindleshaped morphology, pseudopodia formation and increased cell scattering. In contrast, HepG2 cells overexpressing Cx32 became more rounded and showed no/decreased filamentous or lamellipodia and increased intercellular connectivity (Fig. 3A). With the downregulation of $\mathrm{Cx} 32$, a decreased expression of E-cadherin and an increased expression of vimentin were detected in the SMMC-7721 cells. For the HepG2 cells transfected with Cx32 cDNA, the EMT markers showed opposite changes (Fig. 3B). Immunofluorescence assay further confirmed the changes of expression of E-cadherin and vimentin by $\mathrm{Cx} 32$ (Fig. 3C). These results suggest that downregulation of $\mathrm{Cx} 32$ in HCC accelerated cell migration and invasion accompanied by induction of EMT.

Snail mediates Cx32-regulated EMT in HCC cells. In order to further clarify the molecular mechanism of EMT regulated by $\mathrm{Cx} 32$, we subsequently investigated the effect of Cx32 on EMT-related transcription factors Snail, Slug and Twist-1. As shown in Fig. 4A, Cx32 downregulation in the SMMC-7721 cells led to a significant increase of Snail expression, but not of Slug and Twist-1. Whereas, overexpression of Cx32 in HepG2 cells resulted in a significant decrease of Snail with no alteration in Slug or Twist-1 expression. Immunofluorescence assay further demonstrated that Cx32 negatively regulated Snail expression in both HCC cell lines (Fig. 4B). To assess whether the expression change of Snail was due to transcriptional regulation, Snail mRNA level was evaluated by qRT-PCR analysis. As shown in Fig. 4C, the expression of Snail mRNA was also negatively regulated by $\mathrm{Cx} 32$.

To further investigate whether Snail mediates the Cx32induced EMT, Snail was knocked down in SMMC-7721 cells using siRNA and overexpressed in HepG2 cells using cDNA. Knockdown of Snail resulted in reversal of the Cx32 inhibition induced EMT-associated phenotype changes including EMT-like morphology, downregulation of E-cadherin, upregulation of vimentin, and an enhanced ability of cell invasion in the SMMC-7721 cells (Fig. 4D-F). Similarly, overexpression of Snail can counteract the biological effects of upregulation of Cx32 in HepG2 cells (Fig. 4D-F). These data indicated that $\mathrm{Cx} 32$ regulated EMT-associated invasion in HCC cells by affecting the expression of Snail.

Wnt signaling is involved in Snail-mediated EMT in HCC cells. Considering the general function of $\mathrm{Cx} 32$ acting as a membrane protein (10), we hypothesized that $\mathrm{Cx} 32$ was more likely to regulate Snail expression indirectly. $\beta$-catenin is an important epithelial marker which links E-cadherin and $\alpha$-catenin to the cytoskeleton to form a complex maintaining epithelial polarity and intercellular adhesion and is associated closely to EMT (24). As shown in Fig. 5A, there was no significant change in the total protein expression of $\beta$-catenin by $\mathrm{Cx} 32$ regulation, in SMMC-7721 or HepG2 cells. However, expression of phosphorylated $\beta$-catenin (Y654), a status indicating transcriptional activity and nuclear translocation of $\beta$-catenin (25), was increased in Cx32 downregulated SMMC7721 cells and decreased in Cx32 overexpressed HepG2 cells. A consistent change was also shown for Wnt-1 (Fig. 5A). The results were confirmed by immunofluorescence assay 
A
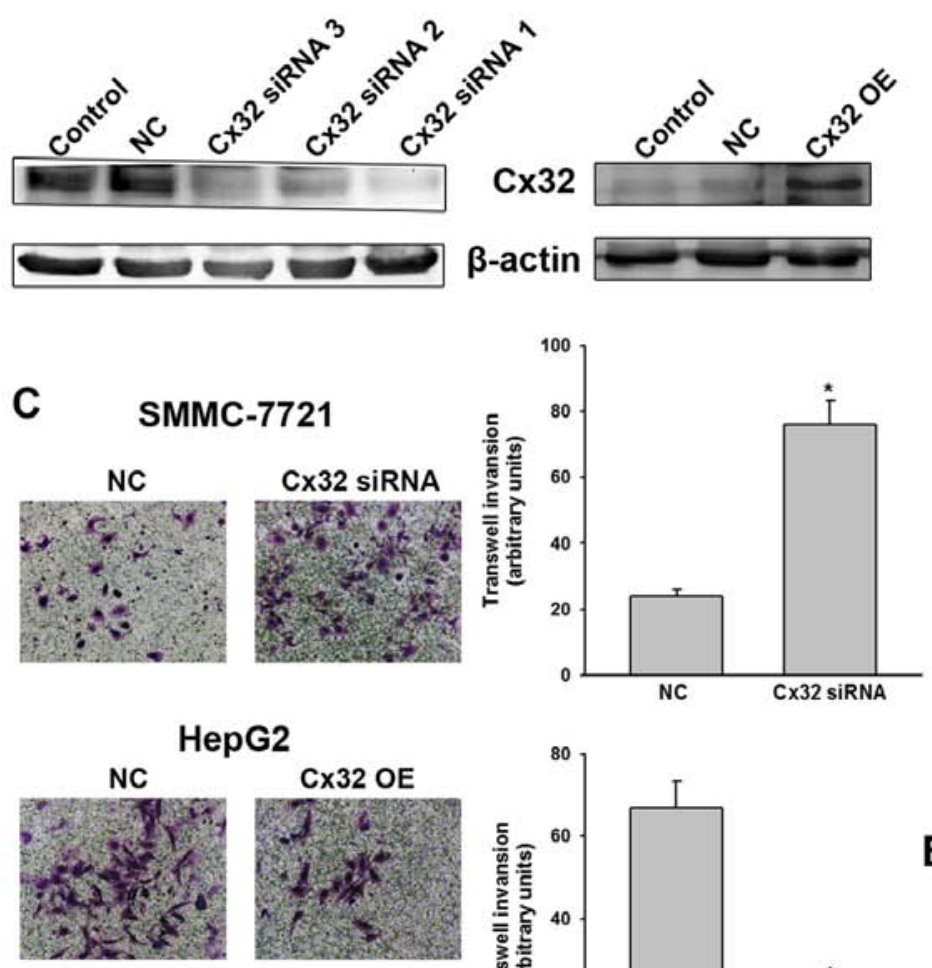

D

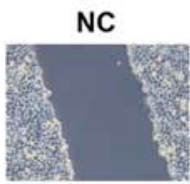

$\mathbf{0 ~ h ~}$

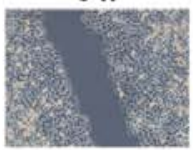

$24 \mathrm{~h}$

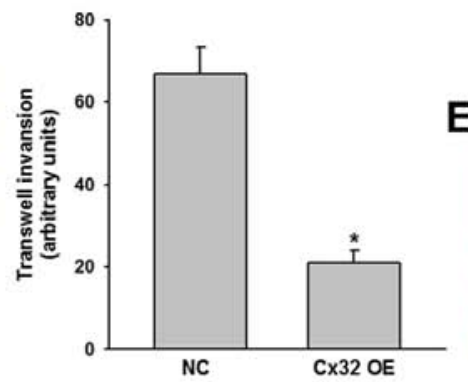

HepG2

E
B

SMMC-7721

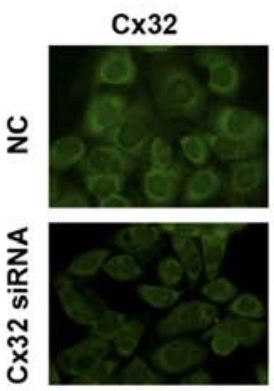

DAPI
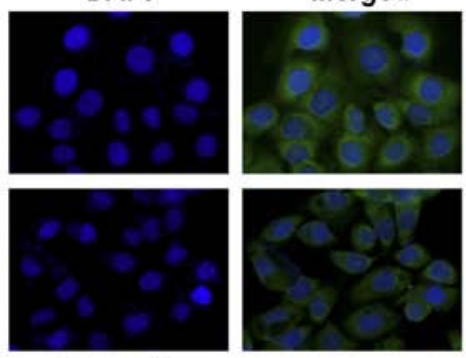

HepG2
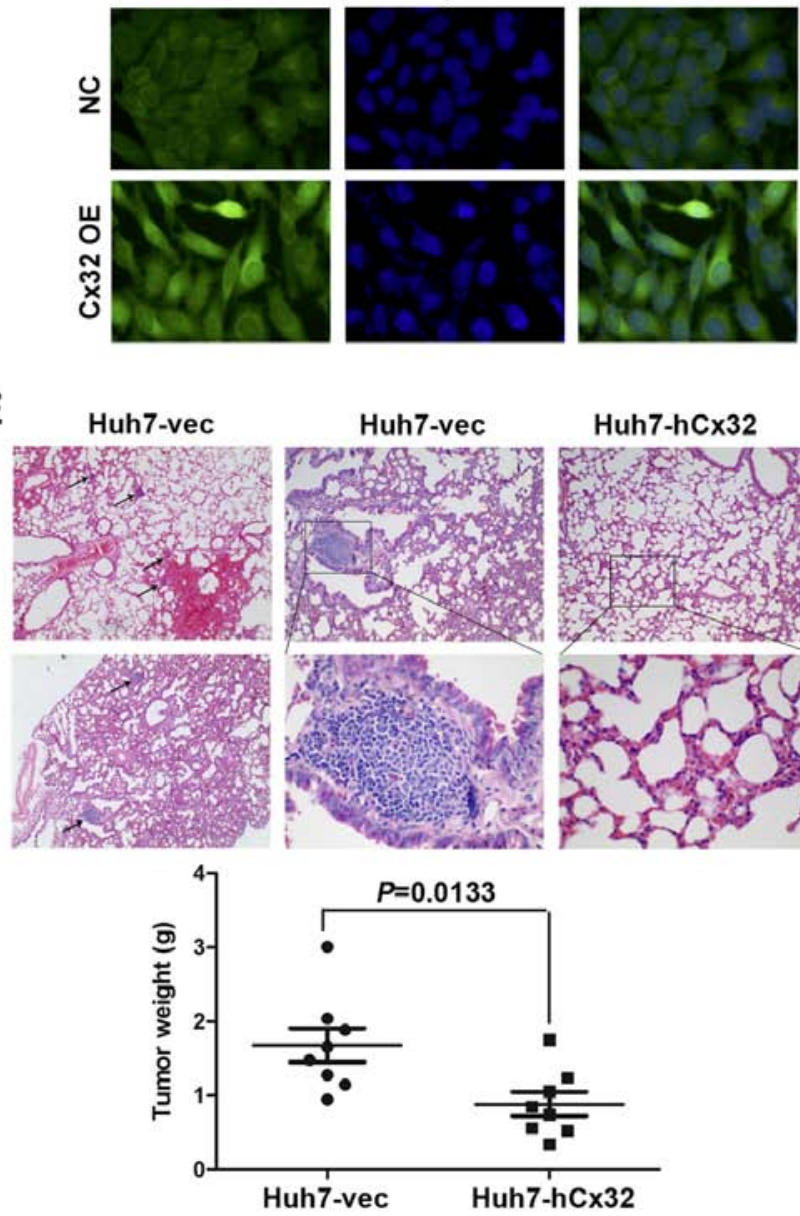

Figure 2. Cx32 inhibits HCC cell migration and invasion in vitro and tumor metastases in vivo. (A) Left panel, western blot analysis was conducted to detect the inhibitory efficacy of Cx32 siRNA in SMMC-7721 cells. Right panel, western blot analysis was performed to confirm an overexpression of Cx32 in HepG2 cells following transfection by pEX-2/hCx32. (B) Fluorescence images showed decreased Cx32 expression in SMMC-7721 cells transfected with Cx32 siRNA, and enhanced Cx32 expression in HepG2 cells with Cx32 cDNA transfection, by the immunofluorescence assay (original magnification, x400). (C) Transwell invasion assay was conducted to measure the invasive capacity of Cx32 downregulated SMMC-7721 and Cx32 overexpressed HepG2 cells (original magnification, x200). (D) Wound healing assay was performed to investigate the migratory potential of Cx32 downregulated SMMC-7721 and Cx32 overexpressed HepG2 cells (original magnification, x100). (E) Upper panel, the pulmonary metastatic nodules with H\&E staining were observed under a microscope (original magnification, x40, x100 and x400, respectively). Blank arrows were used to indicate multiple lung metastases. Lower panel, the mean tumor weight of different groups. NC, negative control; OE, overexpression. Data represent the mean $\pm \mathrm{SEM}$ of three independent experiments. $\mathrm{P}<0.01 \mathrm{vs.} \mathrm{NC}$.

by showing a change of nuclear translocation of $\beta$-catenin (Fig. 5B).

In an effort to establish that Snail-mediated EMT in HCC cells was due to the Wnt signaling pathway activation, the effect of DKK-1, the inhibitor of the Wnt signaling pathway (26), was determined. As expected, DKK-1 reversed the EMT phenotype changes and the enhancement of cell invasion induced by $\mathrm{Cx} 32$ downregulation in SMMC-7721 cells (Fig. 5C-E). Moreover,
DKK-1 addition abolished the upregulation of Snail induced by $\mathrm{Cx} 32$ downregulation both in protein and mRNA levels (Fig. 5F). Taken together, our data indicated that downregulation of Cx32 upregulates Snail expression and promotes EMT through activation of the Wnt signaling pathway in HCC cells.

Cx32 is associated with EMT markers in HCC tissues. To obtain clinical evidence of the correlation between $\mathrm{Cx} 32$, 
A

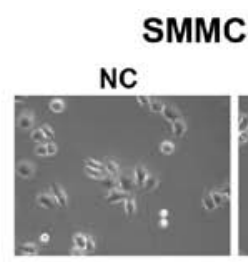

$\mathbf{O h}$

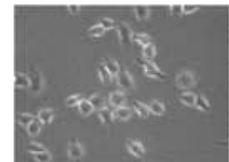

$6 \mathrm{~h}$

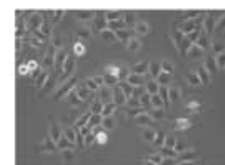

$24 \mathrm{~h}$

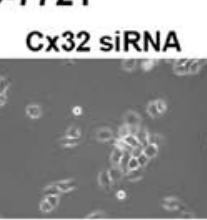

$\mathrm{Oh}$

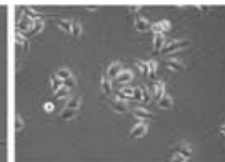

$6 \mathrm{~h}$

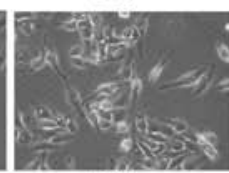

$24 \mathrm{~h}$

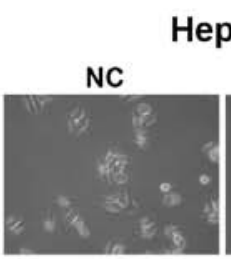

$\mathrm{Oh}$

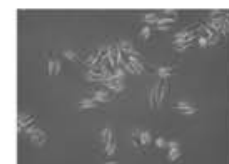

$12 \mathrm{~h}$

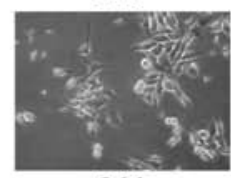

$24 \mathrm{~h}$
HepG2

Cx32 OE

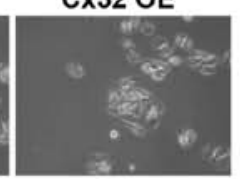

$\mathbf{O h}$

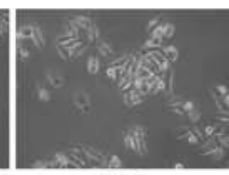

$12 \mathrm{~h}$

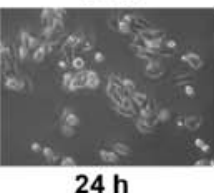

B

SMMC-7721

HepG2

Control NC Cx32 siRNA

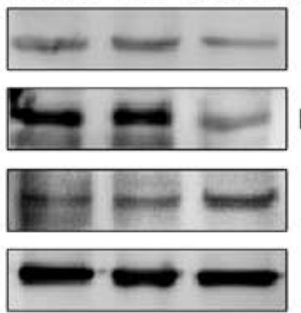

Cx32

Control NC $\mathrm{C} \times 32 \mathrm{OE}$

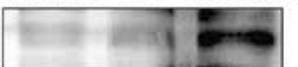

E-cadherin

Vimentin

$\beta$-actin
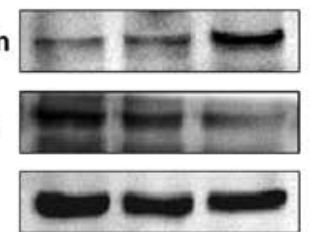

C

SMMC-7721

SMMC-7721

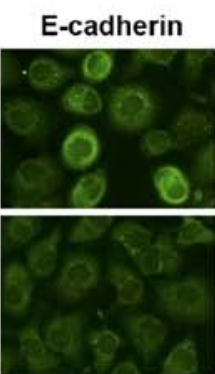

DAPI
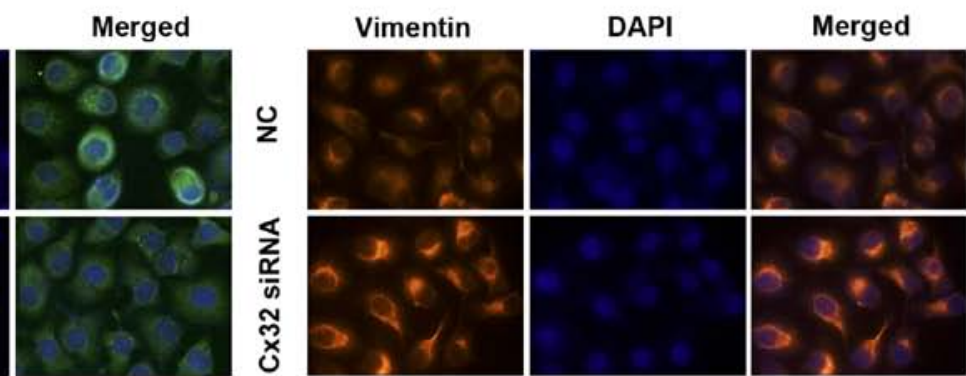

HepG2
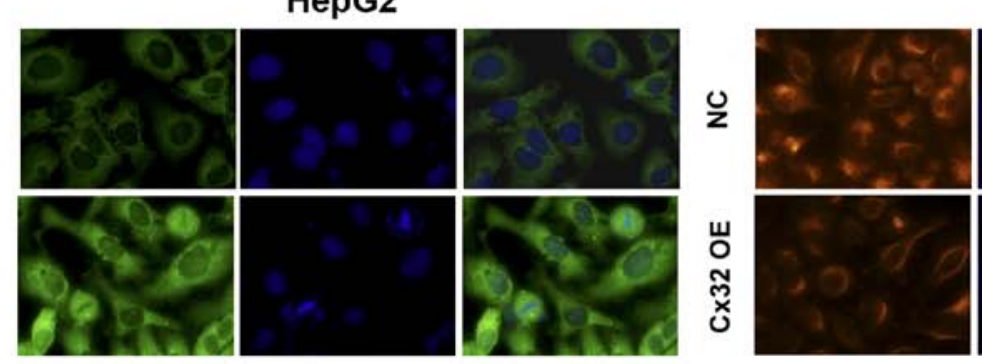

HepG2

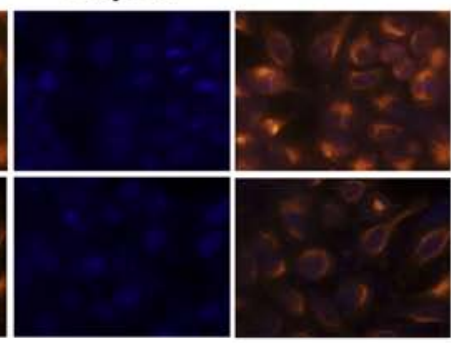

Figure 3. Modulation of Cx32 in HCC cells influences EMT or MET process in vitro. (A) Cell morphological changes of Cx32 downregulated SMMC-7721 and Cx32 overexpressed HepG2 cells as observed by microscopy. Images are representative of three independent experiments (original magnification, x200). (B) Effect of Cx32 on expression of EMT-related proteins. E-cadherin and vimentin were examined in Cx32 downregulated SMMC-7721 and Cx32 overexpressed HepG2 cells by western blot analysis. (C) Immunofluorescence assay was performed to assess the expression of markers of epithelial and mesenchymal phenotypes (original magnification, $\mathrm{x} 400$ ). NC, negative control; OE, overexpression.

E-cadherin, $\beta$-catenin and Snail, we tested the expression of these proteins in an additional set of $34 \mathrm{HCC}$ tissues by IHC staining. Cx32 was identified in 14 of $34 \mathrm{HCC}$ tissues and the positive particles were weakly stained and mainly located in the cytoplasm. A significant reduction or loss of E-cadherin expression was detected in 18 cases. Snail stained both in 
A

SMMC-7721

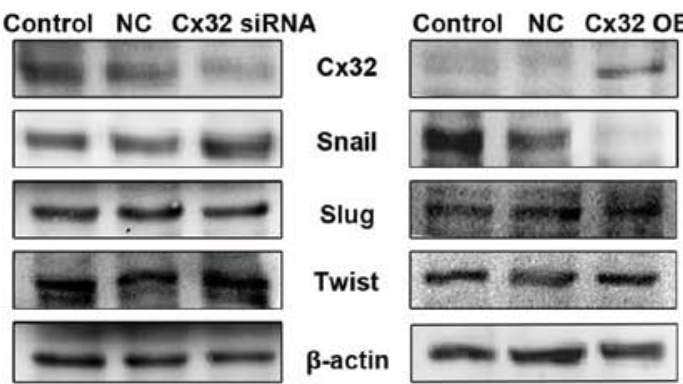

C

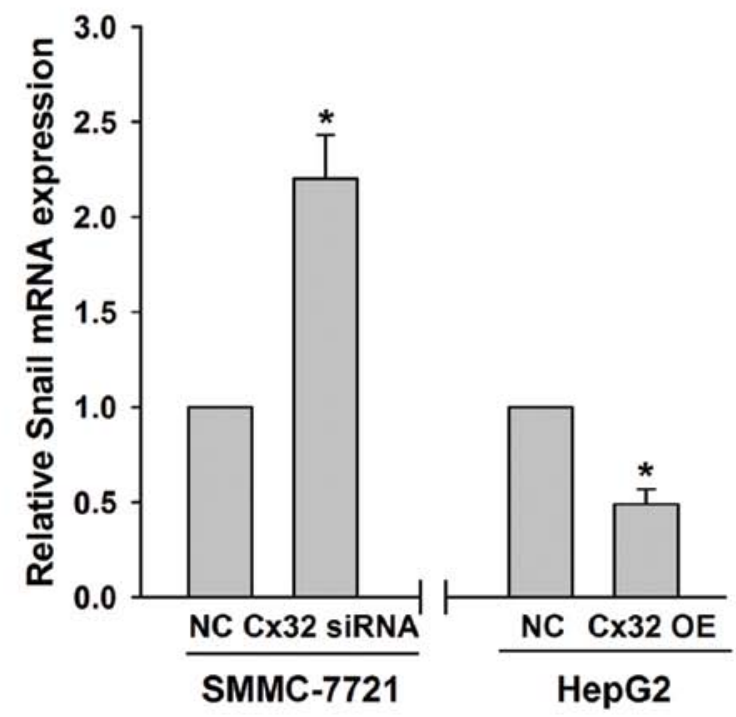

E

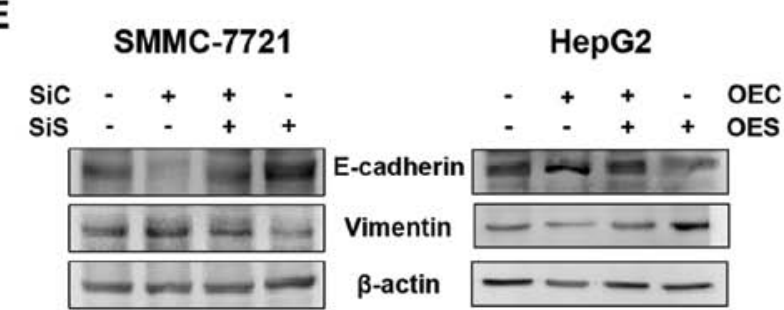

$\mathbf{F}$

SMMC-7721

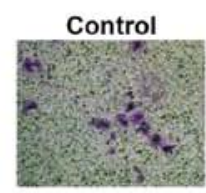

$\mathrm{SiC}+\mathrm{SiS}$

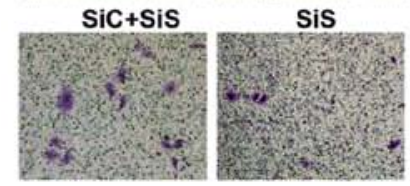

\section{$\mathrm{SiC}$}

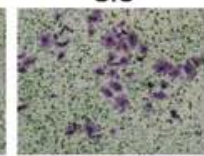

Sis

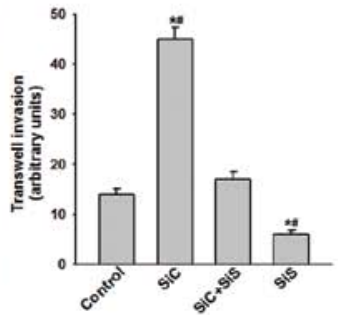

B
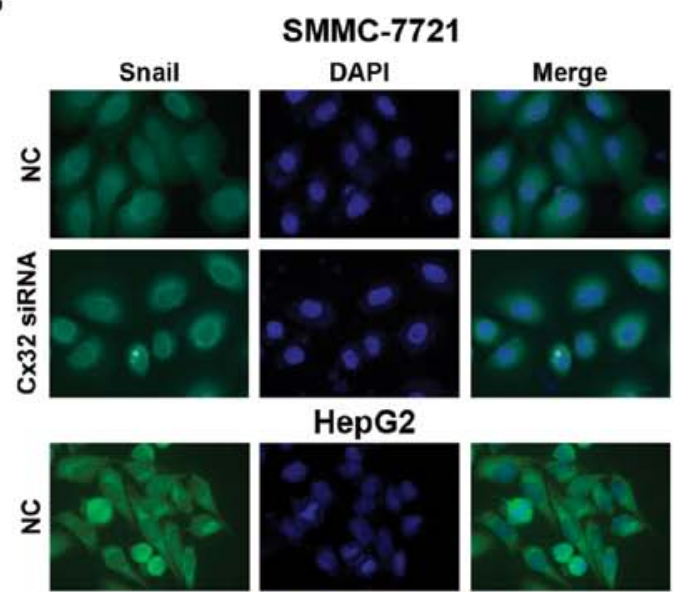

HepG2

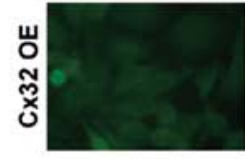

D
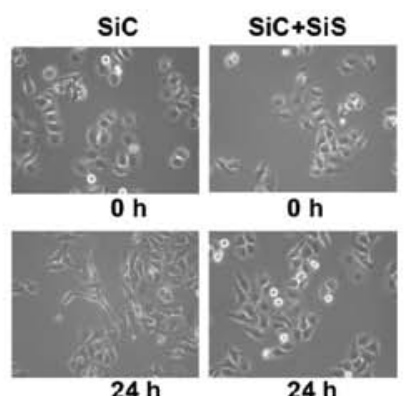

HepG2

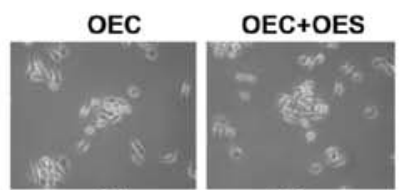

$\mathrm{Oh}$

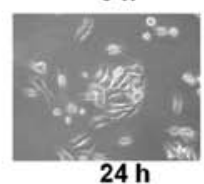

$\mathrm{Oh}$

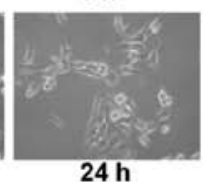

\section{HepG2}

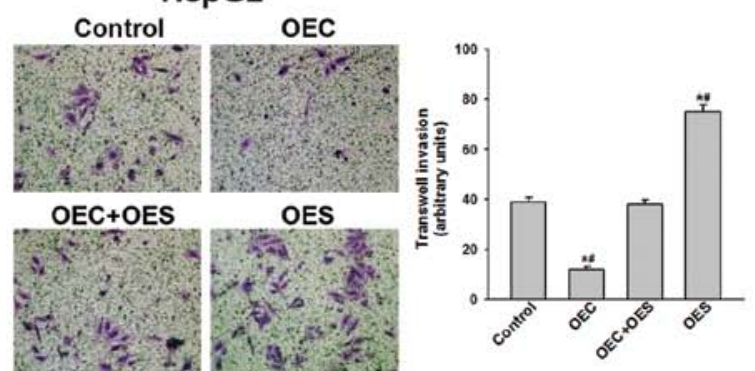

Figure 4. Cx32 exerts its effect through negative regulation of Snail expression. (A) Knockdown of Cx32 increased Snail but not Slug or Twist-1 expression in SMMC-7721 cells, while overexpression of Cx32 decreased Snail but not Slug or Twist-1 expression in HepG2 cells, as evidenced by western blot analysis. (B) Expression of Snail was negatively regulated by Cx32 as confirmed by immunofluorescence assay (original magnification, $\mathrm{x} 400$ ). (C) Snail mRNA was detected by real-time PCR in different groups. (D) Cell morphological changes of SMMC-7721 and HepG2 cells in the presence of both Cx32 and Snail modulation (original magnification, x200). (E) Silencing of Snail in SMMC-7721 cells rescued Cx32 knockdown-induced EMT-related protein changes while upregulation of Snail in HepG2 cells abrogated Cx32 overexpression-induced EMT-related proteins modulation. (F) Invasive capacity of SMMC-7721 and HepG2 cells in the presence of both Cx32 and Snail modulation (original magnification, x200). NC, negative control; OE, overexpression; SiC, siRNA of Cx32; SiS, siRNA of Snail; OEC, overexpression of Cx32; OES, overexpression of Snail. Data represent the mean \pm SEM of three to four independent experiments. ${ }^{*} \mathrm{P}<0.01$ vs. NC (C); ${ }^{\mathrm{P}}<0.01$ vs. control, ${ }^{\#} \mathrm{P}<0.01$ vs. $\mathrm{SiC}+\mathrm{SiS}$ (or OEC+OES) (F). 
A

SMMC-7721

Control NC Cx32 siRNA

20.catenin

\%or $p$-catenin

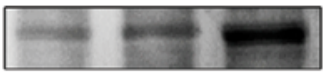

Wnt-1

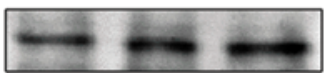

$\beta$-actin

B

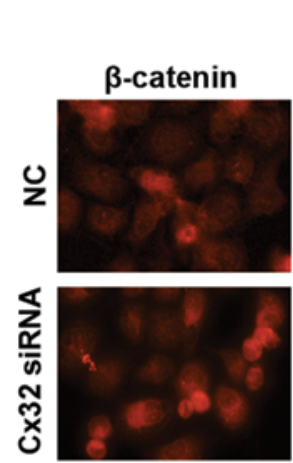

\section{SMMC-7721}

DAPI
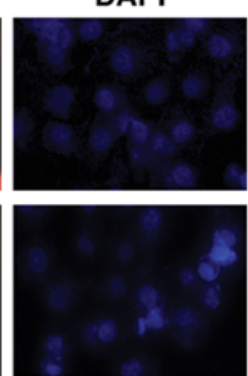

HepG2
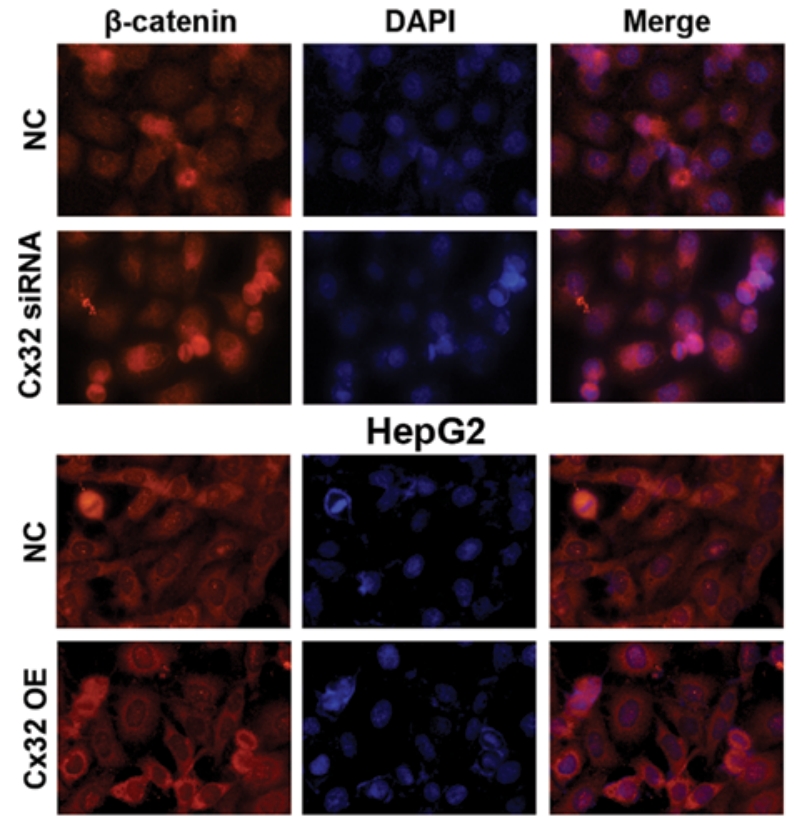

$\mathbf{F}$

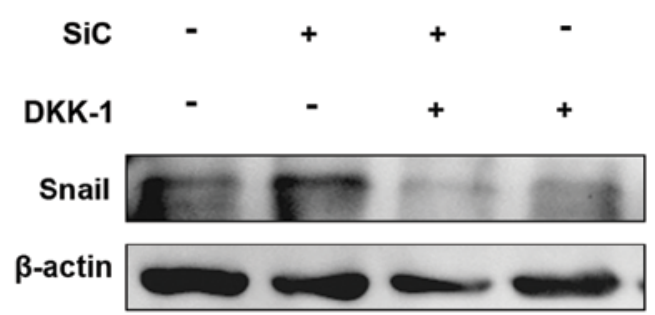

\section{C}
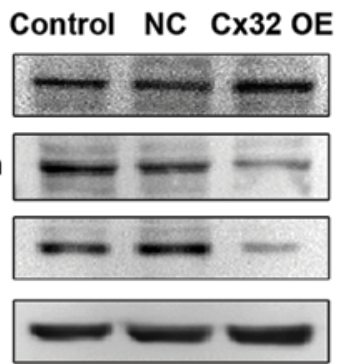
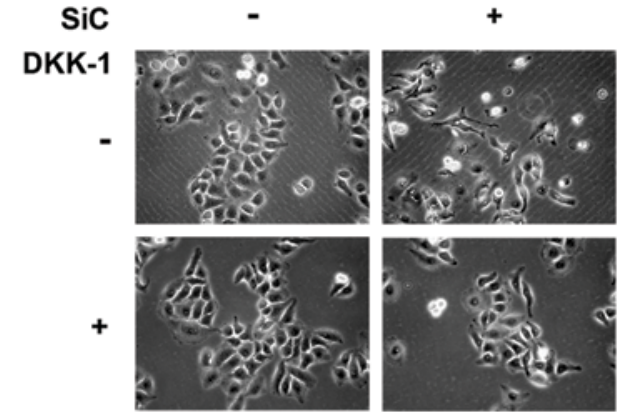

D

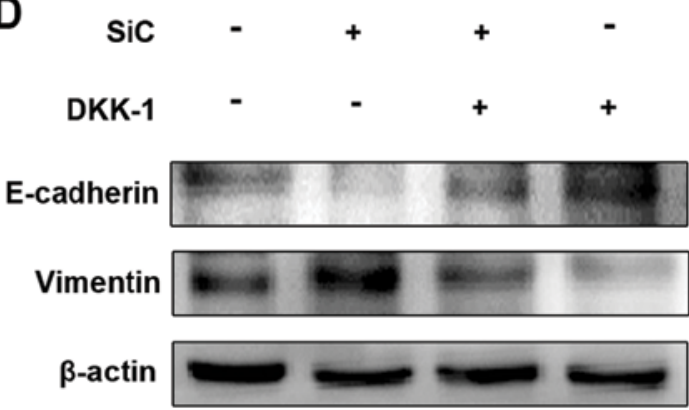

E

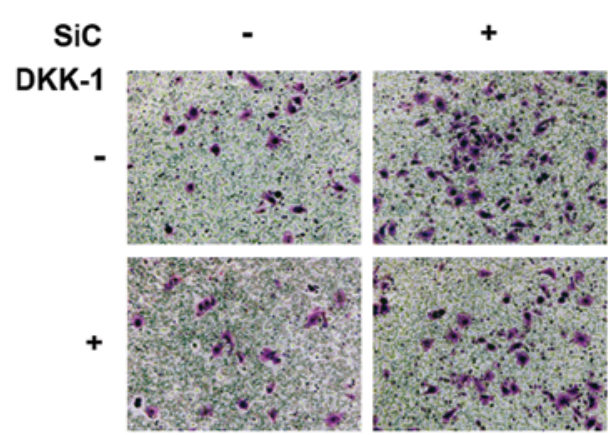

G

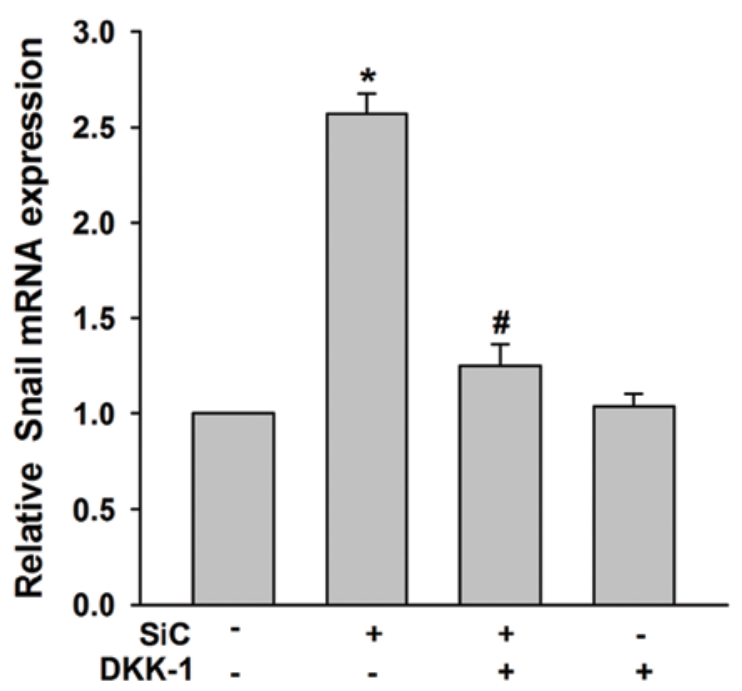

Figure 5. Wnt pathway mediates EMT and upregulation of Snail induced by Cx32 downregulation in SMMC-7721 cells. (A) Effect of Cx32 on expression of total $\beta$-catenin, phosphorylated $\beta$-catenin (Y654) and Wnt-1 by western blot analysis. (B) Effect of Cx32 on $\beta$-catenin expression and localization by immunofluorescence assay. (C-E) SMMC-7721 cells were treated with Cx32 siRNA or (and) DKK-1 (10 $\mu \mathrm{g} / \mathrm{ml}, 48 \mathrm{~h})$ and the cell morphology was observed (C), protein extracts were analyzed for the expression of EMT markers by western blot analysis (D), and ability of cell invasion was analyzed by Transwell assay (E). (F) SMMC-7721 cells were treated with Cx32 siRNA or (and) DKK-1 (10 $\mu \mathrm{g} / \mathrm{ml}, 48 \mathrm{~h})$, Snail protein expression was determined by western blot analysis and mRNA expression was determined by real-time PCR. NC, negative control; OE, overexpression; SiC, siRNA of Cx32. Data represent the mean \pm SEM of four independent experiments. ${ }^{*} \mathrm{P}<0.01$ vs. no $\mathrm{SiC}$ or $\mathrm{DKK}-1 ;{ }^{\#} \mathrm{P}<0.01$ vs. SiC. 

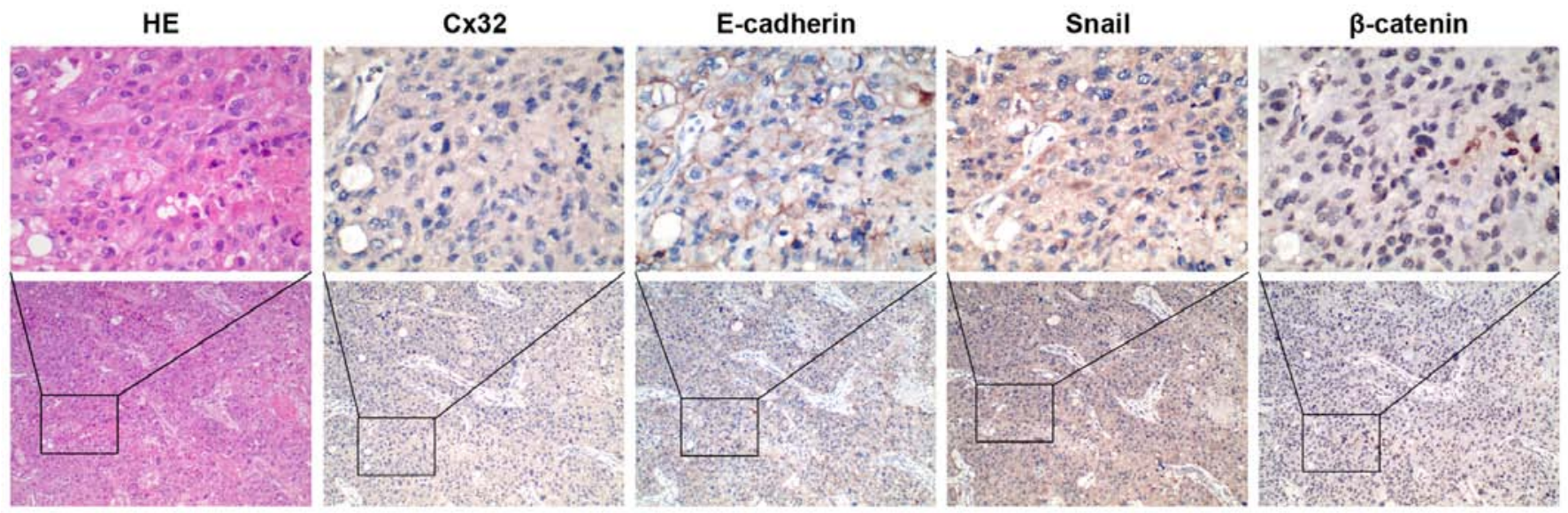

Figure 6. IHC staining of Cx32, E-cadherin, Snail and $\beta$-catenin in HCC tissues. Co-expression of the four indicators from a high grade HCC which indicates Cx32 negative expression, E-cadherin reduced membranous staining, Snail positive expression and $\beta$-catenin nuclear staining (original magnification, x100 and $\mathrm{x} 400)$.

Table IV. The correlation between Cx32 and EMT markers (E-cadherin, Snail and $\beta$-catenin) staining in an additional set of 34 HCC samples.

\begin{tabular}{|c|c|c|c|c|c|c|c|c|c|c|c|c|c|}
\hline & & \multicolumn{2}{|c|}{ E-cadherin } & \multirow[b]{2}{*}{$\mathrm{r}$} & \multirow[b]{2}{*}{ P-value } & \multicolumn{2}{|c|}{$\begin{array}{c}\text { Snail } \\
\text { (nuclear) }\end{array}$} & \multirow[b]{2}{*}{$\mathrm{r}$} & \multirow[b]{2}{*}{ P-value } & \multicolumn{2}{|c|}{$\begin{array}{c}\beta \text {-catenin } \\
\text { (nuclear) }\end{array}$} & \multirow[b]{2}{*}{$\mathrm{r}$} & \multirow[b]{2}{*}{ P-value } \\
\hline & & Loss/reduction & Normal & & & - & + & & & - & + & & \\
\hline \multirow[t]{2}{*}{ Cx32 } & - & 15 & 5 & 0.528 & 0.001 & 4 & 16 & -0.448 & 0.008 & 8 & 12 & -0.457 & 0.007 \\
\hline & + & 3 & 11 & & & 9 & 5 & & & 12 & 2 & & \\
\hline
\end{tabular}

cytoplasm and nucleus and was recorded as positive in the nucleus in 21 cases. For $\beta$-catenin staining, $41.18 \%(14 / 34)$ of HCC cases was positive for nuclear accumulation with concurrent cytoplasmic staining, while all the other samples showed membranous localization. When further analyzed in comparison with expression of EMT markers, Cx32 expression showed a strong correlation with expression of the loss or reduction of E-cadherin $(\mathrm{r}=0.528, \mathrm{P}=0.001)$, nuclear Snail $(\mathrm{r}=-0.448, \mathrm{P}=0.008)$, and nuclear accumulation of $\beta$-catenin $(\mathrm{r}=-0.457, \mathrm{P}=0.007)$ (Table IV, Fig. 6).

\section{Discussion}

While it has been established that $\mathrm{Cx}$ and $\mathrm{Cx}$-mediated GJ suppress tumor development during hepatocarcinogenesis (11), the role of Cxs in tumor progression, including invasion and metastasis is still controversial. Zhao et al (23) demonstrated the exogenously overexpressed $\mathrm{Cx} 32$ protein suppressed the metastatic ability of human $\mathrm{HCC}$ cells both in vitro and in vivo. The anti-invasive effect of Cx32 has also been reported in other type of tumors such as kidney (13) and lung (14) cancer, indicating $\mathrm{Cx} 32$ as a tumor suppressor gene. However, accumulating evidence has shown that Cx26 (15) and Cx32 (16) are highly expressed in lymph node metastases of patients with lung or breast cancer and correlated with a poor prognosis. Breast cancer and melanoma cells utilize Cxs to initiate brain metastasis by enhancing vascular invasion (17). One reason for the discrepancy in the role of Cxs in tumor progression is the fact that cancer involves multiple stages from onset to progression and metastasis and Cxs cannot provide benefit at all of these stages (10).

The present study observed a negative relationship between Cx32 expression and lymph node metastasis from clinical data, and further confirmed the suppressive role of $\mathrm{Cx} 32$ in $\mathrm{HCC}$ invasion and metastasis both in vitro and in vivo. Considering the tumorigenicity and Cx32 expression pattern among the different cell lines in vitro, we performed in vivo metastasis analysis using Huh7 cells overexpressing Cx32. However, using Huh7 Tet-off Cx32 cells, Li et al (27) obtained the opposite result by showing that overexpression of cytoplasmic $\mathrm{Cx} 32$ protein induced metastasis in vivo. Regarding the difference between these two results, it was speculated that it might be related to the different $\mathrm{Cx} 32$ inducible system and cell culture condition. Cx32 was induced to localize only in cytoplasm in the latter system, however, in the present study, besides the increase in amount of $\mathrm{Cx} 32$, the possible more formation of Cx32-mediated GJ that may contribute to the suppression of metastasis could also play a role. Moreover, the inhibitory role of Cx32 was also observed in the other two HCC cell lines, including the SMMC-7721 cells and the HepG2 cells, which is in line with the recently reported results from Zhao et al (23). Our findings are highly favorable from a therapeutic perspective, because it is difficult to design strategies that could specifically upregulate Cx32 in a primary HCC tumor while 
decreasing off-target adverse effect due to the cytoplasmic localization. Thus, the data support the notion of utilizing Cx32 as a therapeutic target in HCC treatment.

Clarification of the molecular mechanism of Cx32 in inhibiting invasion and metastasis can help to fully understand the biological effects of this gene in HCC. EMT is an important basis for obtaining the malignant phenotype of hepatocytes (4). Moreover, CX-mediated GJ has recently been proposed to serve as an intercellular glue to suppress EMT and cancer metastasis (9), we thus explored the role of EMT in Cx32-mediated function. Upon the downregulation of Cx32 expression, SMMC-7721 cells gained characteristics of EMT including apparent changes in morphology, downregulation of E-cadherin, upregulation of vimentin, enhancement of cell migration and invasion ability. In contrast, after upregulating Cx32 in HepG2 cells, the cells exhibited opposite biological behavior. The ability of $\mathrm{Cx} 43$ to inhibit EMT has been demonstrated by $\mathrm{Yu}$ et al (8), thus, it is not surprising that $\mathrm{Cx} 32$, as an another important member of the Cx family, can also play a role in EMT process. In the present study, we identified EMT as novel target for $\mathrm{Cx} 32$ action, and for the first time provided a mechanistic link between Cx32 anti-metastatic activity and EMT modulation.

Molecular switches for the EMT program are multiple, in which transcription factors play an important regulatory role (28). We subsequently found that $\mathrm{Cx} 32$ negatively regulate the expression of Snail but not Slug and Twist-1, and Snail could counteract Cx32-mediated in vitro biological effects. Snail is a zinc-finger transcriptional repressor, which has been identified as a potential oncogene in various tumors (29), capable of triggering EMT and promoting metastasis in $\mathrm{HCC}(5,6)$. In the present study, the positive rate of nuclear Snail in clinical specimens of HCC was up to $61.76 \%$ (21/34), and was negatively correlated with the expression of Cx32 and E-cadherin. The data were consistent with a previous report showing Snail, rather than Slug, downregulates E-cadherin expression and promotes human HCC invasion (20). Thus, these data clearly demonstrated that downregulation of Cx32 facilitates HCC invasion and metastasis through Snail-mediated EMT.

Wnt signaling is shown to activate the transcription, protein stability, as well as nuclear localization of Snail through the inhibition of GSK $3 \beta$ (30,31). Furthermore, during hepatocarcinogenesis, it has been indicated that the $\mathrm{Wnt} / \beta$-catenin signaling is abnormally activated (32), and GSK-3 $\beta$ inactivation is associated with low expression of Cx32 (33). Thus, there is a possible link between Cx32, Wnt signaling and Snail. We then explored whether $\mathrm{Wnt} / \beta$-catenin pathway was involved in the Cx32-mediated Snail regulation. Together with Wnt-1, phosphorylated $\beta$-catenin (Y654) expression was negatively regulated by $\mathrm{Cx} 32$ in $\mathrm{HCC}$ cells, but the total $\beta$-catenin protein level was not changed significantly. Inhibition of canonical Wnt pathway attenuated the upregulation of Snail and induction of EMT response to $\mathrm{Cx} 32$ downregulation. Moreover, nuclear accumulation of $\beta$-catenin in HCC tissues was directly correlated with the reduced $\mathrm{Cx} 32$. These results provide molecular and clinical evidence to support the fact that $\mathrm{Cx} 32$ regulates Snail expression through the Wnt/ $\beta$-catenin pathway in HCC.

In conclusion, the present study provides new insight into the role of Cx32 in EMT and metastasis of HCC. We demonstrated that downregulation of $\mathrm{Cx} 32$ upregulates Snail expression and induces EMT in HCC cells through activation of Wnt $/ \beta$-catenin pathway. Thus, our data not only provide further evidence of targeted increase of Cx32 as a beneficial strategy to control HCC progression and metastasis, but also reveals the underlying mechanism of a novel Cx32/ $\beta$-catenin/Snail pathway as a promising new molecular target against advanced HCC.

\section{Acknowledgements}

The present study was supported by the National Natural Science Foundation of China (no. 81402514 to Y.Y. and 81572458 to Q.W.), the grant from the Natural Science Foundation of Anhui Province (no. 1408085QH166 to Y.Y.), and the Natural Science Research key Project of Education Office of Anhui Province (no. KJ2014A152 to Q.W.). We thank the Biochemical and Medical Engineering Research Center of Anhui Province and the Scientific Research Platform of Bengbu Medical College for instrument support.

\section{References}

1. Torre LA, Bray F, Siegel RL, Ferlay J, Lortet-Tieulent J and Jemal A: Global cancer statistics, 2012. CA Cancer J Clin 65: 87-108, 2015.

2. Rahbari NN, Mehrabi A, Mollberg NM, Müller SA, Koch M, Büchler MW and Weitz J: Hepatocellular carcinoma: Current management and perspectives for the future. Ann Surg 253: 453-469, 2011.

3. Cauchy F, Soubrane O and Belghiti J: Liver resection for HCC: Patient's selection and controversial scenarios. Best Pract Res Clin Gastroenterol 28: 881-896, 2014.

4. Cervantes-Arias A, Pang LY and Argyle DJ: Epithelialmesenchymal transition as a fundamental mechanism underlying the cancer phenotype. Vet Comp Oncol 11: 169-184, 2013.

5. Zhou ZJ, Dai Z, Zhou SL, Hu ZQ, Chen Q, Zhao YM, Shi YH, Gao Q, Wu WZ, Qiu SJ, et al: HNRNPAB induces epithelial-mesenchymal transition and promotes metastasis of hepatocellular carcinoma by transcriptionally activating SNAIL. Cancer Res 74: 2750-2762, 2014.

6. Fu XT, Dai Z, Song K, Zhang ZJ, Zhou ZJ, Zhou SL, Zhao YM, Xiao YS, Sun QM, Ding ZB, et al: Macrophage-secreted IL-8 induces epithelial-mesenchymal transition in hepatocellular carcinoma cells by activating the JAK2/STAT3/Snail pathway. Int J Oncol 46: 587-596, 2015.

7. Wu Y, Liu H, Weng H, Zhang X, Li P, Fan CL, Li B, Dong PL, Li L, Dooley S, et al: Glypican-3 promotes epithelial-mesenchymal transition of hepatocellular carcinoma cells through ERK signaling pathway. Int J Oncol 46: 1275-1285, 2015.

8. Yu M, Zhang C, Li L, Dong S, Zhang N and Tong X: Cx43 reverses the resistance of A549 lung adenocarcinoma cells to cisplatin by inhibiting EMT. Oncol Rep 31: 2751-2758, 2014.

9. Mao XY, Li QQ, Gao YF, Zhou HH, Liu ZQ and Jin WL: Gap junction as an intercellular glue: Emerging roles in cancer EMT and metastasis. Cancer Lett 381: 133-137, 2016.

10. Naus CC and Laird DW: Implications and challenges of connexin connections to cancer. Nat Rev Cancer 10: 435-441, 2010.

11. Vinken M, Henkens T, De Rop E, Fraczek J, Vanhaecke T and Rogiers V: Biology and pathobiology of gap junctional channels in hepatocytes. Hepatology 47: 1077-1088, 2008.

12. Mesnil M,Crespin S, Avanzo JL and Zaidan-Dagli ML: Defective gap junctional intercellular communication in the carcinogenic process. Biochim Biophys Acta 1719: 125-145, 2005.

13. Fujimoto E, Sato H, Shirai S, Nagashima Y, Fukumoto K, Hagiwara H, Negishi E, Ueno K, Omori Y, Yamasaki H, et al: Connexin32 as a tumor suppressor gene in a metastatic renal cell carcinoma cell line. Oncogene 24: 3684-3690, 2005.

14. King TJ and Lampe PD: The gap junction protein connexin32 is a mouse lung tumor suppressor. Cancer Res 64: 7191-7196, 2004.

15. Ito A, Koma Y, Uchino K, Okada T, Ohbayashi C, Tsubota N and Okada M: Increased expression of connexin 26 in the invasive component of lung squamous cell carcinoma: Significant correlation with poor prognosis. Cancer Lett 234: 239-248, 2006. 
16. Kanczuga-Koda L, Sulkowska M, Koda M, Rutkowski R and Sulkowski S: Increased expression of gap junction proteinconnexin 32 in lymph node metastases of human ductal breast cancer. Folia Histochem Cytobiol 45 (Suppl 1): S175-S180, 2007.

17. Stoletov K, Strnadel J, Zardouzian E, Momiyama M, Park FD, Kelber JA, Pizzo DP, Hoffman R, VandenBerg SR and Klemke RL: Role of connexins in metastatic breast cancer and melanoma brain colonization. J Cell Sci 126: 904-913, 2013.

18. Yang Y, Zhu J, Zhang N, Zhao Y, Li WY, Zhao FY, Ou YR, Qin SK and Wu Q: Impaired gap junctions in human hepatocellular carcinoma limit intrinsic oxaliplatin chemosensitivity: A key role of connexin 26. Int J Oncol 48: 703-713, 2016.

19. Regidor PA, Regidor M, Schindler AE and Winterhager E: Aberrant expression pattern of gap junction connexins in endometriotic tissues. Mol Hum Reprod 3: 375-381, 1997.

20. Sugimachi K, Tanaka S, Kameyama T, Taguchi K, Aishima S, Shimada M, Sugimachi K and Tsuneyoshi M: Transcriptional repressor snail and progression of human hepatocellular carcinoma. Clin Cancer Res 9: 2657-2664, 2003.

21. Wu Q, Wang R, Yang Q, Hou X, Chen S, Hou Y, Chen C, Yang Y, Miele L, Sarkar FH, et al: Chemoresistance to gemcitabine in hepatoma cells induces epithelial-mesenchymal transition and involves activation of PDGF-D pathway. Oncotarget 4 : 1999-2009, 2013.

22. Edwards GO, Jondhale S, Chen T and Chipman JK: A quantitative inverse relationship between connexin 32 expression and cell proliferation in a rat hepatoma cell line. Toxicology 253: 46-52, 2008

23. Zhao B, Zhao W, Wang Y, Xu Y, Xu J, Tang K, Zhang S, Yin Z, $\mathrm{Wu} \mathrm{Q}$ and Wang $\mathrm{X}$ : Connexin32 regulates hepatoma cell metastasis and proliferation via the p53 and Akt pathways. Oncotarget 6: 10116-10133, 2015.

24. Heuberger $\mathbf{J}$ and Birchmeier W: Interplay of cadherin-mediated cell adhesion and canonical Wnt signaling. Cold Spring Harb Perspect Biol 2: a002915, 2010.
25. van Veelen $\mathrm{W}$, Le $\mathrm{NH}$, Helvensteijn W, Blonden L, Theeuwes M, Bakker ER, Franken PF, van Gurp L, Meijlink F, van der Valk MA, et al: $\beta$-catenin tyrosine 654 phosphorylation increases Wnt signalling and intestinal tumorigenesis. Gut 60: 1204-1212, 2011

26. Aguilera O, Fraga MF, Ballestar E, Paz MF, Herranz M, Espada J, García JM, Muñoz A, Esteller M and González-Sancho JM: Epigenetic inactivation of the Wnt antagonist DICKKOPF-1 (DKK-1) gene in human colorectal cancer. Oncogene 25: 4116-4121, 2006

27. Li Q, Omori Y, Nishikawa Y, Yoshioka T, Yamamoto Y and Enomoto K: Cytoplasmic accumulation of connexin32 protein enhances motility and metastatic ability of human hepatoma cells in vitro and in vivo. Int J Cancer 121: 536-546, 2007.

28. Moreno-Bueno G, Portillo F and Cano A: Transcriptional regulation of cell polarity in EMT and cancer. Oncogene 27: 6958-6969, 2008.

29. Wang Y, Shi J, Chai K, Ying X and Zhou BP: The role of Snail in EMT and tumorigenesis. Curr Cancer Drug Targets 13: 963-972, 2013.

30. Yook JI, Li XY, Ota I, Hu C, Kim HS, Kim NH, Cha SY, Ryu JK, Choi YJ, Kim J, et al: A Wnt-Axin2-GSK3beta cascade regulates Snaill activity in breast cancer cells. Nat Cell Biol 8: 1398-1406, 2006.

31. Bachelder RE, Yoon SO, Franci C, de Herreros AG and Mercurio AM: Glycogen synthase kinase-3 is an endogenous inhibitor of Snail transcription: Implications for the epithelialmesenchymal transition. J Cell Biol 168: 29-33, 2005.

32. Kim M, Lee HC, Tsedensodnom O, Hartley R, Lim YS, Yu E, Merle P and Wands JR: Functional interaction between Wnt3 and Frizzled-7 leads to activation of the Wnt/beta-catenin signaling pathway in hepatocellular carcinoma cells. J Hepatol 48: 780-791, 2008

33. Plante I, Charbonneau M and Cyr DG: Activation of the integrinlinked kinase pathway downregulates hepatic connexin32 via nuclear Akt. Carcinogenesis 27: 1923-1929, 2006. 